\title{
Oxidation of primary amines to ketones.
}

\author{
Deborah A. Knowles, ${ }^{a}$ Christopher J. Mathews ${ }^{b}$ and Nicholas C. O. Tomkinson*a \\ ${ }^{a}$ School of Chemistry, Main Building, Cardiff University, Park Place, Cardiff, CF10 3AT, U.K. \\ ${ }^{\mathrm{b}}$ Chemistry Department, Syngenta, Jealotts Hill International Research Centre, Bracknell, Berkshire, RG42 6EY, U.K. \\ Fax: +44(0)2920874030 \\ E-mail: tomkinsonnc@ cardiff.ac.uk \\ Received: The date will be inserted once the manuscript is accepted.
}

\begin{abstract}
A simple method for the oxidation of primary amines to the corresponding ketones that proceeds in the presence of both moisture and air is described. Treatment of an amine with benzoyl peroxide in the presence of caesium carbonate, followed by warming of the hydroxylamine product to $50-70{ }^{\circ} \mathrm{C}$ leads directly to the ketone. The method is shown to be effective for both benzylic and aliphatic substrates.
\end{abstract}

Key words: Amine, oxidation, hydroxylamine, benzoyl peroxide, ketone.

The ability of the chemist to manipulate the carbonyl group in a chemo-, stereo- and enantioselective manner has bestowed upon it a central role in synthetic chemistry. ${ }^{1}$ New methods with which to prepare this functionality from readily available precursors are therefore of great use to the synthetic chemist.

Amines represent a significant class of available building blocks as well as fundamental synthetic intermediates which are readily accessible. There have been a number of reports describing the oxidation of amines to a wide variety of functional groups including imines, amides, nitriles, aldehydes and ketones. Early methods reported for this transformation include the use of stoichiometric transition metal reagents including nickel, ${ }^{2}$ mercury, ${ }^{3}$ lead, ${ }^{4}$ manganese, ${ }^{5}$ iron, ${ }^{6}$ and zinc $^{7}$ derived species. More recently, catalytic methods have been described using palladium ${ }^{8}$ as well as tungsten, ${ }^{9}$ rhodium $^{10}$ ruthenium $^{11}$ and manganese ${ }^{12}$ salts. Stoichiometric methods avoiding the use of transition metals have also been developed using iodosobenzene, ${ }^{13} \mathrm{IBX},{ }^{14}$ sulfonyl peroxides, ${ }^{15}$ and benzoquinones. ${ }^{16}$ These methods represent important alternatives to perform the overall oxidation of primary amines, with varied levels of scope and limitations in substrate tolerance and reaction conditions. Of the transition-metal free methods each optimised method requires anhydrous reaction conditions and the use of an inert atmosphere. Circumventing these practical considerations would represent an advance in the methods available for the overall transformation. Within this letter we describe a simple method for the oxidation of primary amines to the corresponding ketones that proceeds under mild reaction conditions in the presence of both moisture and air, offering a practical alternative to existing methodology.

As part of our investigations into the chemistry of hydroxylamines ${ }^{17,18,19,20,21}$ we reacted $N$-cyclohexyl- $O$ benzoyl hydroxylamine (2) with one equivalent of heptan-4-one (1) and were surprised to observe the $\alpha$ functionalised cyclohexanone $\mathbf{7}$ as the major product. Rationalising that this could have arisen through decom- position of the reagent to give the imine $\mathbf{5}$ followed by condensation with a second molecule of hydroxylamine 2 to give the intermediate enamine 6. Subsequent [3,3]sigmatropic rearrangement followed by hydrolysis of the resulting imine then led to the observed product 7 . Intrigued that if we were able to stop this process at the intermediate imine $\mathbf{5}$ the transformation would represent a new method for amine oxidation we sought to examine this reaction further.

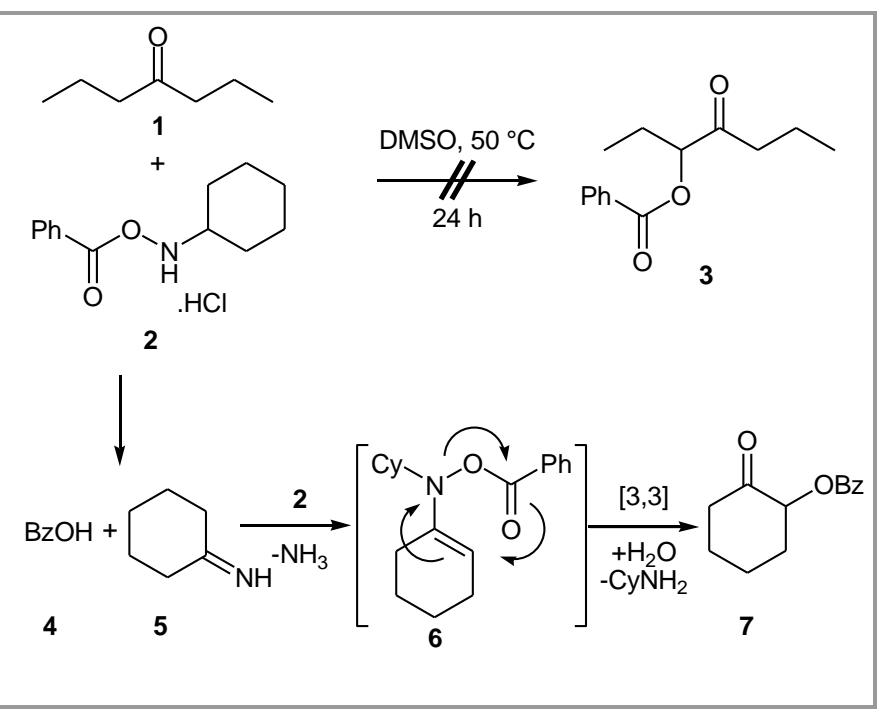

Scheme 1

Preparation of the substrates for the development of this transformation used a robust and convenient method reported by Phanstiel for the conversion of amines to $O$ benzoyl hydroxylamines. ${ }^{22}$ Our key transformation was optimised with the phenethylamine derived hydroxylamine 8 (Table 1). ${ }^{23}$ Use of $\mathbf{8 . H C l}$ in chloroform at $50{ }^{\circ} \mathrm{C}$ proved to be inefficient $(18 \%)$ and resulted in a number of unidentified by-products (entry 1 ). Heating of the free base 8 resulted in recovery of starting material after a 48 hour reaction period (entry 2). Addition of DBU (1 equivalent) significantly accelerated the reaction and provided the product in an encouraging 30\% yield (entry 3). Examination of alternative solvents showed polar solvents to be more effective with DMF emerging as the optimal reaction medium (entries 3-5). Changing the base to caesium carbonate improved the yield further with acetophenone (9) being isolated in an excellent $84 \%$ yield (entry 7). It was also found that catalytic quantities of caesium carbonate could be used with 0.5 equivalents 
(entry 8 ) and 0.1 equivalents (entry 9) giving the product in 76 and $71 \%$ isolated yield respectively.

\begin{tabular}{|c|c|c|c|c|c|}
\hline \multicolumn{2}{|c|}{8} & \multicolumn{3}{|c|}{9} & \\
\hline Entry & Reagent & Base & Solvent & Temp ${ }^{\circ} \mathrm{C}$ & $\%$ Yield $^{\mathrm{e}}$ \\
\hline 1 & 8. $\mathrm{HCl}$ & None & $\mathrm{CHCl}_{3}$ & 50 & 18 \\
\hline 2 & 8 & None & $\mathrm{CHCl}_{3}$ & 50 & 0 \\
\hline 3 & 8 & DBU & $\mathrm{CHCl}_{3}$ & 50 & 30 \\
\hline 4 & 8 & DBU & $\mathrm{PhMe}$ & 50 & 34 \\
\hline 5 & 8 & DBU & DMF & 50 & 66 \\
\hline $6^{\mathrm{b}}$ & 8 & DBU & DMF & 70 & 70 \\
\hline 7 & 8 & $\mathrm{Cs}_{2} \mathrm{CO}_{3}$ & DMF & 50 & 84 \\
\hline $8^{c}$ & 8 & $\mathrm{Cs}_{2} \mathrm{CO}_{3}$ & DMF & 50 & 76 \\
\hline $9^{d}$ & 8 & $\mathrm{Cs}_{2} \mathrm{CO}_{3}$ & DMF & 50 & 71 \\
\hline
\end{tabular}

${ }^{\mathrm{a}}$ All reactions performed at $0.5 \mathrm{M}$ concentration in the presence of 1 equivalent of base for 24 hours unless stated.

$\mathrm{b} 2$ equivalents of base added.

${ }^{c} 0.5$ equivalents of base added.

${ }^{\mathrm{d}}$ Reaction carried out for 48 hours with 0.1 equivalents of base.

${ }^{\mathrm{e}}$ Isolated yield.

Having established efficient conditions for the conversion of $\mathbf{8}$ to acetophenone (9) we examined a series of alternative $O$-benzoyl hydroxylamines to determine some of the scope of this transformation (Table 2). The reaction worked efficiently for both benzylic (entries 17) and aliphatic (entries 8-12) amines. Both electron donating (entries 2 and 4) and withdrawing (entry 3) substituents were tolerated on the aromatic ring as well as increased steric crowding around the reactive nitrogen (entries 5 and 6). The conversion of $\mathrm{N}$-benzyl- $\mathrm{O}$ benzoyl hydroxylamine to benzaldehyde was particularly facile, the reaction proceeding at room temperature, however, this was accompanied by significant decomposition leading to a reduced isolated yield of the product (41\%; entry 7). It was expected that enolisable aldehydes would be inherently unstable to the basic reaction conditions required for this transformation, therefore these substrates were not examined. The conditions are mild enough to be able to carry out the reaction on substrates that lead to enolisable ketones (entries 8-12) with all substrates examined effectively leading to the expected product, suggesting the reaction should have a reasonable scope.

\section{Table 2 Scope of conversion}

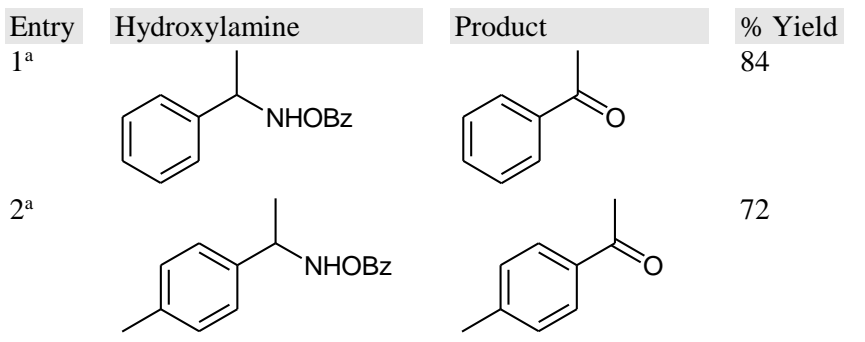

$3^{\mathrm{a}}$<smiles>CCOCCNC(C)c1ccc(F)cc1</smiles><smiles>CC(=O)c1ccc(F)cc1</smiles>

$4^{\mathrm{a}}$<smiles>COc1ccc(C(C)NC(=O)OCc2ccccc2)cc1</smiles><smiles>COc1ccc(C(C)=O)cc1</smiles>

$5^{\mathrm{a}}$<smiles>CCC(NC(CC)c1ccccc1)c1ccccc1</smiles><smiles>CCC(=O)c1ccccc1</smiles>

$6^{\mathrm{a}}$<smiles>CCOC(=O)OCCc1ccccc1CNCc1ccccc1</smiles><smiles>CCCCCC(=O)c1ccccc1C(=O)c1ccccc1</smiles>

$12^{c}$<smiles>CCCCCC(C)NC(=O)OCc1ccccc1</smiles><smiles>CCCCCC(C)=O</smiles>

53

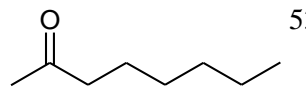

${ }^{\text {a }}$ Reaction performed at $50^{\circ} \mathrm{C}$.

${ }^{\mathrm{b}}$ Reaction performed at $25^{\circ} \mathrm{C}$.

${ }^{\mathrm{c}}$ Reaction performed at $70^{\circ} \mathrm{C}$.

${ }^{\mathrm{d}}$ Product isolated as the 2,4-DNPH derivative.

Finally, having developed effective conditions for the conversion of $O$-benzoyl hydroxylamines to the corresponding ketone we sought to discover if a one-pot method for the direct conversion of primary amines to ketones could also be established. The synthesis of $O$ benzoyl hydroxylamines from primary amines has been shown to be most efficient under basic reaction conditions. Reported bases for this transformation include sodium carbonate, ${ }^{22}$ sodium hydroxide, ${ }^{24}$ tertbutylamine $^{25}$ and disodium hydrogen phosphate. ${ }^{26}$ Pleasingly, caesium carbonate was found to be effective 
in the reaction of primary amines with benzoyl peroxide allowing for the direct conversion of primary amines to ketones. Treatment of a cooled DMF solution of caesium carbonate (1.5 equivalents) and benzoyl peroxide (1 equivalent) with the primary amine (1.2 equivalents) followed by warming of the reaction mixture led directly to the corresponding ketone (Table 3 ). The reaction was effective for both benzylic (entries 1-4) and aliphatic (entry 5) primary amines and provides a convenient alternative for this overall transformation.

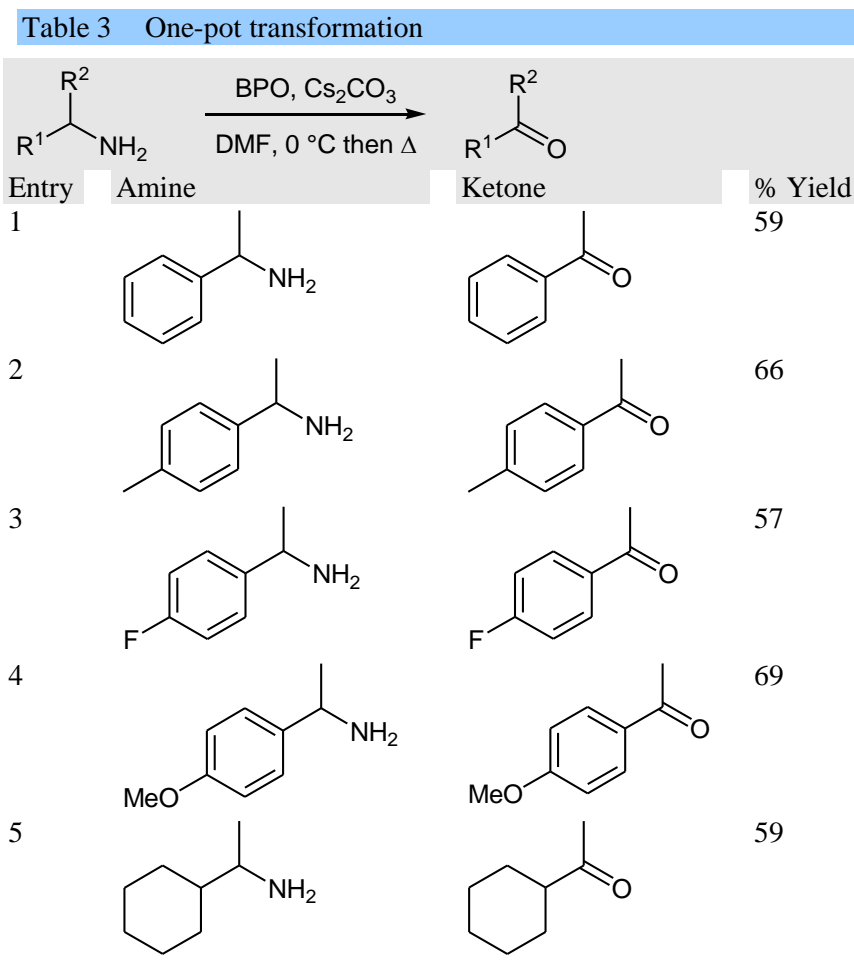
mines can efficiently be converted into the corresponding ketones by treatment with caesium carbonate. The reactions are simple to perform in the presence of both moisture and air and lead to the product in good to excellent yield. A direct method for the conversion of primary amines to ketones was also shown to be possible by reaction of a primary amine and benzoyl peroxide under basic reaction conditions. The reactions are effective for both benzylic and aliphatic primary amines and a variety of substitution patterns on the parent amine.

Typical procedure for conversion of $\mathrm{N}$-alkyl- $\mathrm{O}$ benzoyl hydroxylamines to ketones

$N$ - $\alpha$-Methyl benzyl- $O$-benzoyl hydroxylamine $(100 \mathrm{mg}$, $0.41 \mathrm{mmol})$ was dissolved in DMF $(0.59 \mathrm{~mL})$ at ambient temperature. Caesium carbonate $(135 \mathrm{mg}, 0.41 \mathrm{mmol})$ was added and the resulting reaction mixture was heated at $50{ }^{\circ} \mathrm{C}$ overnight. The resulting reaction mixture was allowed to cool and purified directly by column chromatography, eluting with $20 \%$ ethyl acetate/petrol, to give acetophenone (42 $\mathrm{mg}, 84 \%$ ) as a clear colourless oil; IR (thin film): 1683, 1599, 1582, 1449, 1359, 1266, 1180,
1078, 1025, 955, 760, $690 \mathrm{~cm}^{-1} .{ }^{1} \mathrm{H}$ NMR $(400 \mathrm{MHz}$, $\left.\mathrm{CDCl}_{3}\right): \delta=7.85(\mathrm{~d}, J=7.15 \mathrm{~Hz}, 2 \mathrm{H}), 7.45(\mathrm{t}, J=7.34$ $\mathrm{Hz}, 1 \mathrm{H}), 7.4-7.3(\mathrm{~m}, 2 \mathrm{H}), 2.5(\mathrm{~s}, 3 \mathrm{H}) .{ }^{13} \mathrm{C}$ NMR $(100$ $\left.\mathrm{MHz}, \mathrm{CDCl}_{3}\right): \delta=198.1,137.1,133.1,128.6,128.3$, 26.6. MS (EI): $m / z=120.06[\mathrm{M}]^{+}$.

\section{Typical procedure for the one-pot conversion of pri- mary amines to ketones:}

Benzoyl peroxide (326 mg, $1.01 \mathrm{mmol}, 75 \%$ ) was dissolved in DMF $(2.53 \mathrm{~mL})$ and cooled to $0{ }^{\circ} \mathrm{C}$. Caesium carbonate (493 mg, $1.51 \mathrm{mmol}$ ) was added with stirring followed by cyclohexyl ethylamine $(0.18 \mathrm{~mL}, 1.21$ mmol). The resulting reaction mixture was stirred at $0{ }^{\circ} \mathrm{C}$ for 2 hours before warming to r.t. Thin layer chromatography was used to confirm complete consumption of benzoyl peroxide before heating at $50{ }^{\circ} \mathrm{C}$ overnight. The resulting reaction mixture was purified directly by column chromatography, eluting with $20 \%$ ethyl acetate/petrol, to give cyclohexyl methyl ketone $(75 \mathrm{mg}$, $59 \%$ ) as a clear colourless oil; IR (thin film): 2931, 2854, $1706 \mathrm{~cm}^{-1} .{ }^{1} \mathrm{H}$ NMR $\left(400 \mathrm{MHz}, \mathrm{CDCl}_{3}\right): \delta=2.3-2.3(\mathrm{~m}$, $1 \mathrm{H}), 2.05$ (s, $3 \mathrm{H}), 1.85-1.8$ (m, $2 \mathrm{H}), 1.75-1.7$ (m, $2 \mathrm{H})$, 1.65-1.55 (m, $1 \mathrm{H}), 1.3-1.05(\mathrm{~m}, 5 \mathrm{H}) .{ }^{13} \mathrm{C}$ NMR $(100$ $\left.\mathrm{MHz}, \mathrm{CDCl}_{3}\right): \delta=212.2,51.4,28.4,27.8,25.8,25.6$. MS (EI): $m / z=126.22[\mathrm{M}]^{+}$.

\section{Acknowledgment}

The authors thank Dr Tom Sheppard for insightful discussions, the EPSRC and Syngenta for financial support and the Mass Spectrometry Service, Swansea for high-resolution spectra.

\section{References}

(1) Modern Carbonyl Chemistry, Otera, J. (Ed), Weinheim; Chichester: Wiley-VCH, 2000.

(2) Nakagawa, K.; Onoue, H.; Sugita, J. Chem. Pharm. Bull. 1964, 12, 1135-1138.

(3) Orito, K.; Hatakeyama, T.; Takeo, M.; Uchiito, S.; Tokuda, M.; Suginome, H. Tetrahedron 1998, 54, 8403-8410.

(4) Stephens, F. F.; Bower, J. D. J. Chem. Soc. 1949, 29712972.

(5) (a) Rawalay, S. S.; Shechter, H. J. Org. Chem. 1967, 32, 3129-3131. (b) Noureldin, N. A.; Bellegarde, J. W. Synthesis 1999, 939-942.

(6) Audette, R. J.; Quail, J. W.; Smith, P. J. Tetrahedron Lett. 1971, 12, 279-282.

(7) Chen, H. G.; Knochel, P. Tetrahedron Lett. 1988, 29, 67016702.

(8) Miyazawa, A.; Tanaka, K.; Sakakura, T.; Tashiro, M.; Tashiro, H.; Prakash, G. K. S.; Olah, G. A. Chem. Commun. 2005, 2104-2106.

(9) Hamamoto, H.; Suzuki, Y.; Takahashi, H.; Ikegami, S. Tetrahedron Lett. 2007, 48, 4239-4242.

(10) Choi, H.; Doyle, M. P. Chem. Commun. 2007, 745-747.

(11) Murahashi, S.--;.; Komiya, N. In Modern Oxidation Methods Backvall J.-E. Ed.; Wiley-VCH: Weinheim, 2004, 175179.

(12) Larsen, J.; Jørgensen, K. A. J. Chem. Soc., Perkin Trans II 1992, 1213-1217.

(13) Moriarty, R. M.; Vaid, R. K.; Duncan, M. P. Tetrahedron Lett. 1988, 29, 6913-6916.

(14) Nicolaou, K. C.; Mathison, C. J. N.; Montagnon, T. J. Am. Chem. Soc. 2004, 126, 5192-5201.

(15) Hoffman, R. V. J. Am. Chem. Soc. 1976, 98, 6702-6704. 
(16) Corey, E. J.; Achiwa, K. J. Am. Chem. Soc. 1969, 91, $1429-1432$.

(17) For the $\alpha$-oxyacylation of carbonyl compounds see: (a) Beshara, C. S.; Hall, A.; Jenkins, R. L.; Jones, K. L.; Jones, T. C.; Killeen, N. M.; Taylor, P. H.; Thomas, S. P.; Tomkinson, N. C. O. Org. Lett. 2005, 7, 5729-5732. (b) Beshara, C. S.; Hall, A.; Jenkins, R. L.; Jones, T. C.; Parry, R. T.; Thomas, S. P.; Tomkinson, N. C. O. Chem. Commun. 2005, 1478-1480. (c) Jones, T. C.; Tomkinson, N. C. O. Org. Synth. 2007, 233-241.

(18) For the formation of carbamates see: Hall, A.; Huguet, E. P.; Jones, K. L.; Jones, T. C.; Killeen, N. M.; Yau, S. C.; Tomkinson, N. C. O. Synlett 2007, 293-297.

(19) For the formation of carbonates see: Hall, A.; Jones, K. L.; Jones, T. C.; Killeen, N. M.; Porzig, R.; Taylor, P. H.; Yau, S. C.; Tomkinson, N. C. O. Synlett 2006, 3435-3438.

(20) For the $\alpha$-oxysulfonylation of carbonyl compounds see: John, O. R. S.; Killeen, N. M.; Knowles, D. A.; Yau, S. C.; Tomkinson, N. C. O. Org. Lett. 2007, 9, 4009-4012.

(21) For the $N$-arylation of hydroxylamines see: Jones, K. L.; Porzelle, A.; Hall, A.; Woodrow, M. D.; Tomkinson, N. C. O. Org. Lett. 2008, 10, 797-800.

(22) Wang, Q. X.; King, J.; Phanstiel, O., IV. J. Org. Chem. 1997, 62, 8104-8108.

(23) All the known ketones prepared in this study were characterised by ${ }^{1} \mathrm{H}$ NMR, ${ }^{13} \mathrm{C}$ NMR, IR and LRMS.

(24) Roy, R. B.; Swan, G. A. J. Chem. Soc. (C) 1968, 80-85 .

(25) Alewood, P .F.; Calder, I. C.; Richardson, R. L. Synthesis 1981, 121-122.

(26) Berman, A. M.; Johnson, J. S. J. Am. Chem. Soc. 2004, $126,5680-5681$. 
Graphical Abstract:

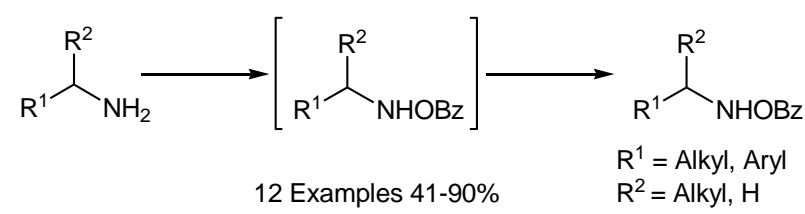

Short Title: Amine oxidation

\section{Manuscript submission checklist}

- Statement of significance of work.

- Full mailing address, telephone and fax numbers, and email address of the corresponding author.

- Paper save as a PDF file.

- Original Word file.

- Original graphic files.

- Graphical abstract.

1 Modern Carbonyl Chemistry, Otera, J. (Ed), Weinheim; Chichester: Wiley-VCH, 2000.

2 Nakagawa, K.; Onoue, H.; Sugita, J. Chem. Pharm. Bull. 1964, 12, 1135-1138.

3 Orito, K.; Hatakeyama, T.; Takeo, M.; Uchiito, S.; Tokuda, M.; Suginome, H. Tetrahedron 1998, 54, 8403-8410.

4 Stephens, F. F.; Bower, J. D. J. Chem. Soc. 1949, 2971-2972.

5 (a) Rawalay, S. S.; Schechter, H. J. Org. Chem. 1967, 32, 3129-3131. (b) Noureldin, N. A.; Bellegarde, J. W. Synthesis 1999, 939-942.

6 Audette, R. J.; Quail, J. W.; Smith, P. J. Tetrahedron Lett. 1971, 12, 279-282.

7 Chen, H. G.; Knochel, P. Tetrahedron Lett. 1988, 29, 6701-6702.

8 Miyazawa, A.; Tanaka, K.; Sakakura, T.; Tashiro, M.; Tashiro, H.; Prakash, G. K. S.; Olah, G. A. Chem. Commun. 2005, 2104-2106.

9 Hamamoto, H.; Suzuki, Y.; Takahashi, H.; Ikegami, S. Tetrahedron Lett. 2007, 48, 4239-4242.

10 Choi, H.; Doyle, M. P. Chem. Commun. 2007, 745-747.

11 Murahashi, S.-I.; Komiya, N. In Modern Oxidation Methods Backvall J.-E. Ed.; Wiley-VCH: Weinheim, 2004, 175 179.

12 Larsen, J.; Jørgensen, K. A. J. Chem. Soc., Perkin Trans II 1992, 1213-1217.

13 Moriarty, R. M.; Vaid, R. K.; Duncan, M. P. Tetrahedron Lett. 1988, 29, 6913-6916.

14 Nicolaou, K. C.; Mathison, C. J. N.; Montagnon, T. J. Am. Chem. Soc. 2004, 126, 5192-5201.

15 Hoffman, R. V. J. Am. Chem. Soc. 1976, 98, 6702-6704.

16 Corey, E. J.; Achiwa, K. J. Am. Chem. Soc. 1969, 91, 1429-1432.

17 For the $\alpha$-oxyacylation of carbonyl compounds see: (a) Beshara, C. S.; Hall, A.; Jenkins, R. L.; Jones, K. L.; Jones, T.

C.; Killeen, N. M.; Taylor, P. H.; Thomas, S. P.; Tomkinson, N. C. O. Org. Lett. 2005, 7, 5729-5732. (b) Beshara, C. S.; Hall, A.; Jenkins, R. L.; Jones, T. C.; Parry, R. T.; Thomas, S. P.; Tomkinson, N. C. O. Chem. Commun. 2005, 1478-1479. (c) Jones, T. C.; Tomkinson, N. C. O. Org. Synth. 2007, 233-241.

18 For the formation of carbamates see: Hall, A.; Huguet, E. P.; Jones, K. L.; Jones, T. C.; Killeen, N. M.; Yau, S. C.; Tomkinson, N. C. O. Synlett 2007, 293-297.

19 For the formation of carbonates see: Hall, A.; Jones, K. L.; Jones, T. C.; Killeen, N. M.; Porzig, R.; Taylor, P. H.; Yau, S. C.; Tomkinson, N. C. O. Synlett 2006, 3435-3438.

20 For the $\alpha$-oxysulfonylation of carbonyl compounds see: John, O. R. S.; Killeen, N. M.; Knowles, D. A.; Yau, S. C.; Tomkinson, N. C. O. Org. Lett. 2007, 9, 4009-4012. 
21 For the $N$-arylation of hydroxylamines see: Jones, K. L.; Porzelle, A.; Hall, A.; Woodrow, M. D.; Tomkinson, N. C. O. Org. Lett. 2008, 10, 797-800.

22 Wang, Q. X.; King, J.; Phanstiel, O., IV. J. Org. Chem. 1997, 62, 8104-8108.

23 All ketones prepared in this study were characterised by 1H NMR, 13C NMR, IR, LRMS and HRMS.

24 Roy, R. B.; Swan, G. A. J. Chem. Soc. (C) 1968, 80-83.

25 Alewood, P .F.; Calder, I. C.; Richardson, R. L. Synthesis 1981, 121-122.

26 Berman, A. M.; Johnson, J. S. J. Am. Chem. Soc. 2004, 126, 5680-5681. 